\title{
Sports nutrition for the recreational athlete
}

CPD

Ben Desbrow, Gary Slater, Gregory R Cox

\section{Background}

Recreational sports participation provides many potential health benefits. However, some athletes experience medical problems associated with, or exacerbated by, a mismanagement of the relationship between their diet and sporting endeavours.

\section{Objective}

The aim of this article is to highlight recent developments in clinical sports nutrition, with a focus on providing evidence-based advice and resources for the management of common medical presentations.

\section{Discussion}

A low dietary energy intake relative to exercise energy demands (ie low energy availability) may result in an array of medical issues. An evidence-based framework for advice on sports supplements is available.
RECREATIONAL SPORTS participation provides many potential benefits to individuals including improved physiological functioning, social interaction and the promotion of mental health. For the majority of recreational athletes (eg those exercising 45-90 minutes, 2-3 times per week), a dietary intake prioritising whole foods in accordance with the Australian Guide to Healthy Eating ${ }^{1}$ will be sufficient to meet an individual's training and competition needs. ${ }^{2}$ However, when exercise demands increase and/or when dietary intake is restricted, specific nutrition strategies should be implemented to promote favourable training adaptations and optimise competition performance while also supporting health and wellbeing. ${ }^{3}$

\section{Fuelling for the demands of training}

A reciprocal relationship exists between nutrition and intense sports participation: frequent participation in sport can create unique nutritional requirements, ${ }^{3}$ while attention to the unique nutritional goals of sportspeople can enhance training and promote optimal competition performances. An athlete's nutritional needs are principally determined by training load (ie intensity, frequency and duration of daily workouts), type of exercise and body mass. However, when

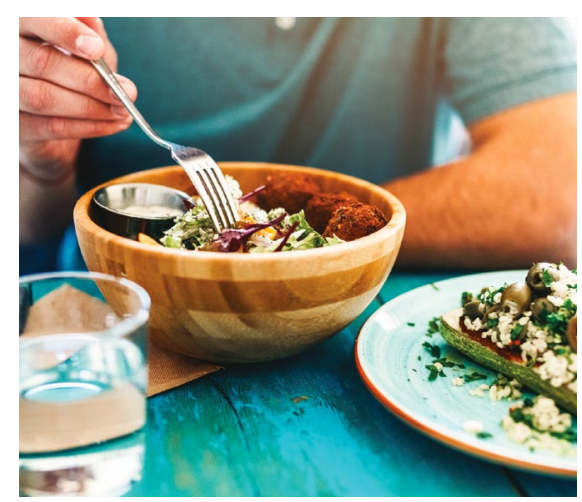

immersed in a sport, individuals are often exposed to the dietary 'norms' (eg cycling and coffee), sports nutrition products (eg drinks, gels and supplements) and body composition expectations that can ultimately influence dietary intake. When training load changes, current sports nutrition recommendations encourage athletes to manipulate dietary intake to support daily performance and optimise adaptations to daily training. ${ }^{4}$ Consumer resources to support a 'food first' approach to matching energy intakes with increased training loads have been developed (Figure 1). ${ }^{5}$ These freely available resources encourage manipulation of 'plate real estate' to better align daily carbohydrate and energy intake with expenditure, a concept known more recently as 'fuel for the work required'. ${ }^{6}$

Such resources may be particularly valuable for education of several groups of recreational athletes (eg endurance athletes, athletes in aesthetic sports, athletes in weight-making sports, adolescent athletes) at risk of consuming an inadequate dietary intake to meet the demands of daily training, health and wellbeing. ${ }^{7}$ Further, some athletes may prioritise nutritional strategies that support leanness over strategies complementing daily fluctuations in training, leaving an individual vulnerable to illness and injury. 


\section{Eating insufficiently and sports participation}

The concept of 'energy availability' is useful for understanding the implications to an athlete of an inadequate dietary energy intake. In simple terms, energy availability (EA) = energy intake - exercise energy expenditure. That is, $\mathrm{EA}=$ calories remaining for biological processes once the energy cost of the sporting activity has been subtracted. Sustained periods of low EA (typically considered $<30 \mathrm{kcal} / \mathrm{kg}$ fat-free mass) or repeated acute (within day) bouts of low EA in very lean individuals can cause impaired physiological functioning, a condition defined as relative energy deficiency in sport (RED-S) ${ }^{8,9}$ RED-S includes impairments of metabolic rate, menstrual function, bone health, immunity, protein synthesis and cardiovascular health (Figure 2).

The impact of RED-S can be significant, and its effects may result in medical presentations with differing signs and/or symptoms. The direct evaluation of RED-S is complicated by the methodological challenges associated with reliably quantifying energy intake, energy expenditure and fat-free mass. For female athletes, irregular or absent menstrual cycles are an obvious clinical indicator of insufficient energy availability. In addition, decreased testosterone/oestrogen and/ or thyroid hormone triiodothyronine $\left(\mathrm{T}_{3}\right)$, or an increase in cortisol, offer potential hormonal assessment parameters of RED-S. However, there is no absolute threshold of low EA that results in amenorrhoea in females or low testosterone in males. Therefore, an individual clinical evaluation including discussion of nutrition attitudes and practices, combined with menstrual history for females and endocrine markers for male and female athletes, is suggested. ${ }^{8}$ In an attempt to simplify the complex clinical assessment and return-to-play decision-making process, the RED-S Clinical Assessment Tool (RED-S CAT) ${ }^{8}$ has been developed (Table 1). The tool provides a simple evaluation of RED-S risk that is easy to implement, based on three categories: 'red light' $=$ cease participation, 'yellow light' $=$ compete medical clearance/ train under supervision, 'green light' = full participation.
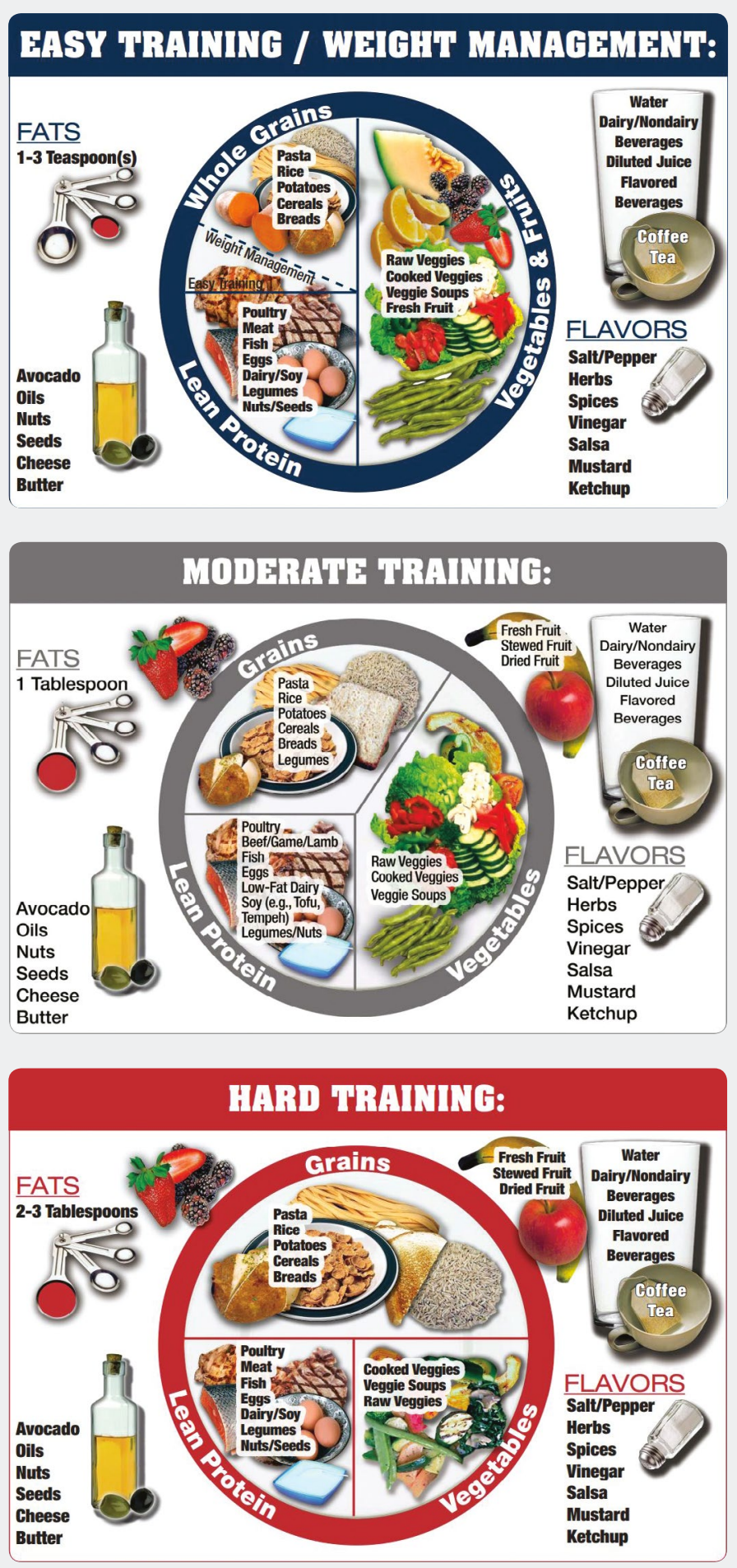

Figure 1. The Athlete's Plate nutrition education tool

Developed by Meyer NL with University of Colorado Colorado Springs' (UCCS) Sport Nutrition Graduate Program in collaboration with the US Olympic Committee's (USOC) Food and Nutrition Services. Reproduced with permission. 


\section{Table 1. The relative energy deficiency in sport decision-based return-to-play model ${ }^{8}$}

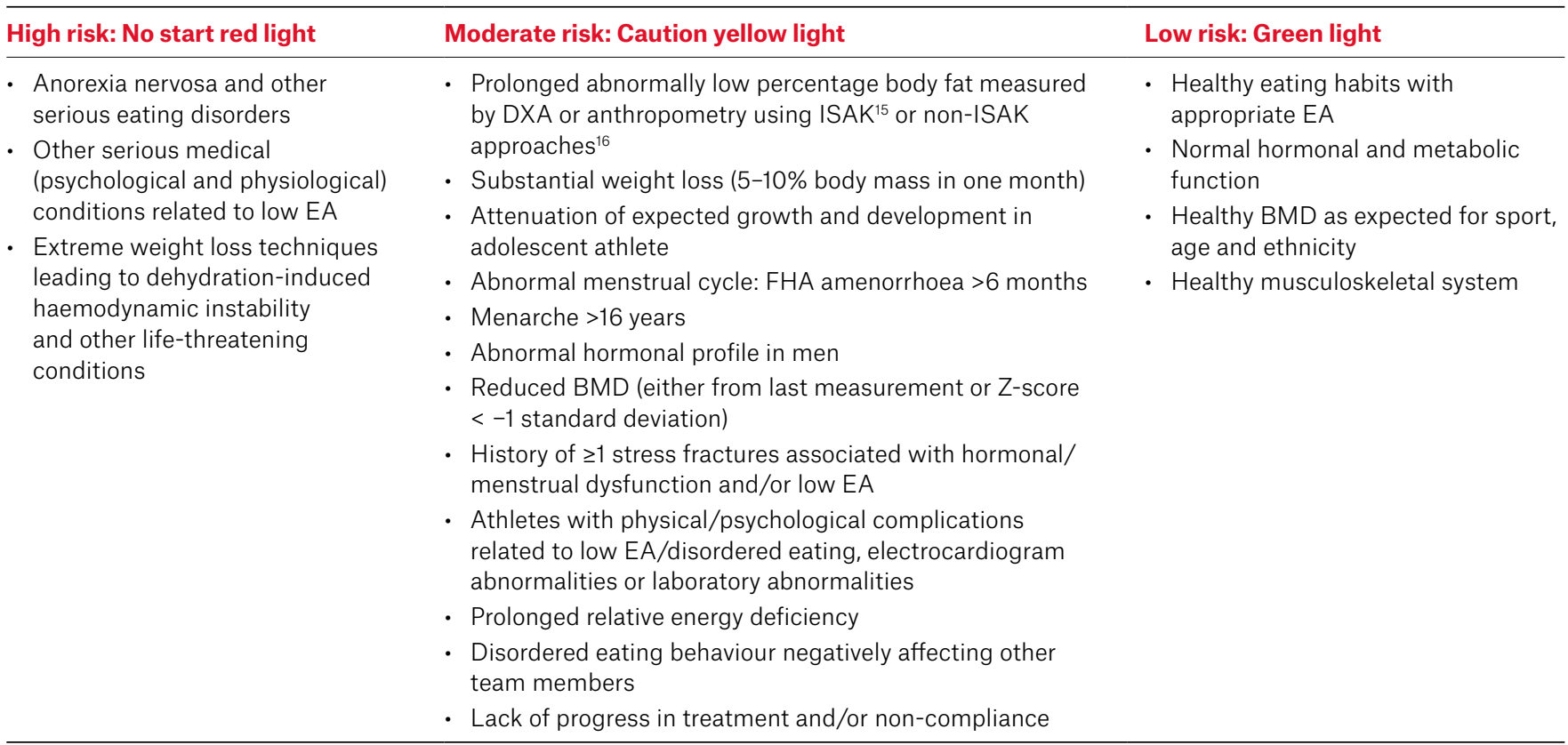

$B M D$, bone mineral density; DXA, dual-energy X-ray absorptiometry; EA, energy availability; FHA, functional hypothalamic amenorrhoea; ISAK, International Society for the Advancement of Kinanthropometry

Reproduced with permission of BMJ Publishing Group Ltd from Mountjoy M, Sundgot-Borgen J, Burke L, et al, The IOC consensus statement: Beyond the female athlete triad - relative energy deficiency in sport (RED-S), Br J Sports Med 2014;48(7):491-97.

\section{Low energy availability in} the general practice context

Two of the most likely scenarios associated with low EA in recreational athletes relate to the presentation of individuals with bone stress injuries and/or compromised iron status.

The impact of low EA on bone is pronounced and occurs quickly, particularly in women. Oestrogendependent and oestrogen-independent mechanisms that affect bone and are affected by low EA have been clearly identified. ${ }^{10}$ In early work undertaken by Loucks and colleagues, a short period of low EA (five days) had a negative impact on bone protein synthesis and mineralisation, ${ }^{11}$ suggesting dietary solutions should be advocated promptly. Given the underlying pathology evolves from the creation of a sustained low EA, an increase in EA should be prioritised.

Regarding iron, the various stages of deficiency for athletic populations are well established (Table 2). ${ }^{12}$ Prevalence studies indicate that approximately $15-35 \%$ of female athletes and $3-11 \%$

Table 2. Definition and assessment of stages of iron deficiency ${ }^{12}$

\begin{tabular}{llll}
\hline & \multicolumn{2}{c}{ Stage } \\
\cline { 2 - 4 } & $\begin{array}{l}\text { 1. Depleted } \\
\text { iron stores }\end{array}$ & $\begin{array}{l}\text { 2. Early functional } \\
\text { iron deficiency }\end{array}$ & $\begin{array}{l}\text { 3. Iron deficiency } \\
\text { anaemia }\end{array}$ \\
\hline Description & $\begin{array}{l}\text { Iron stores in the bone } \\
\text { marrow, liver and spleen } \\
\text { are depleted }\end{array}$ & $\begin{array}{l}\text { Erythropoiesis } \\
\text { diminishes as the iron } \\
\text { supply to the erythroid } \\
\text { marrow is reduced }\end{array}$ & $\begin{array}{l}\text { Haemoglobin production } \\
\text { falls, resulting in } \\
\text { anaemia }\end{array}$ \\
\hline Assessment & $\mathrm{SF}<35 \mu \mathrm{g} / \mathrm{L}$ & $\mathrm{SF}<20 \mu \mathrm{g} / \mathrm{L}$ & $\mathrm{SF}<12 \mu \mathrm{g} / \mathrm{L}$ \\
& $\mathrm{Hb}>115 \mathrm{~g} / \mathrm{L}$ & $\mathrm{Hb}>115 \mathrm{~g} / \mathrm{L}$ & $\mathrm{Hb}<115 \mathrm{~g} / \mathrm{L}$ \\
& $\mathrm{TS}>16 \%$ & $\mathrm{TS}<16 \%$ & $\mathrm{TS}<16 \%$ \\
\hline
\end{tabular}

$H b$, haemoglobin; SF, serum ferritin; TS, transferrin saturation

of male athletes are Stage 1 - Depleted iron stores.

Iron studies can be used alongside haemoglobin to assess an athlete's iron status, as would be done within the sedentary population. However, limitations are associated with the use of ferritin as an indicator of iron status because of its role as an acute phase protein and transient increases during periods of inflammation and following intensive exercise. Furthermore, haemoglobin values are affected by shifts in plasma volume, which, when unaccounted for, may present as pseudoanaemia. Consequently, a recent review by Sim and colleagues made recommendations for considerations and frequency of iron blood screening for athletes (Figure 3) and identified appropriate strategies to address iron deficiency. ${ }^{13}$ 


\section{Advice on sports food and supplements}

A 'food first' policy should be the basis of any athlete's nutrition plan, as recommendations for dietary supplements typically overemphasise the supplements' ability to manipulate performance in comparison to other training and dietary strategies. That said, there may be occasions for the prudent use of medical supplements to address nutrient deficiencies, or sports foods that help the athlete to meet nutritional goals when it is impractical to eat food. Supplements and sports foods represent a lucrative industry that takes advantage of strong marketing to athletes and people who exercise while also reflecting the community interest in supplements.

The use of supplements and sports foods by athletes involves a balance between the potential benefits (eg contribution to health and performance) and risks (eg adverse health events, waste of resources, distraction, poor role modelling, supplement contamination). The Australian Institute of Sport has established an independent, evidencebased Sports Supplement Framework (https://ais.gov.au/nutrition/supplements) to support the judicious use of supplements. ${ }^{14}$

The Framework classifies supplements into four categories (A, B, C and D; Table 3) according to scientific evidence, supporting the use of products that are safe, permitted and effective in improving sports performance.

Performance-based supplements (Category A) include caffeine, bicarbonate, beta-alanine, nitrate, creatine and glycerol; however, their value is specific to particular event characteristics (eg repeated sprint ability). Supplement considerations may also extend to athletes undertaking travel or competing in challenging environments (eg heat and altitude), and individuals with restricted dietary choice (eg vegetarians). Ideally, each athlete should develop a personalised, periodised, and practical nutrition plan - via collaboration with their coach and accredited sports nutrition expert - to optimise their performance. The Sports Dietitian Australia website is useful to locate the nearest sports dietitian,

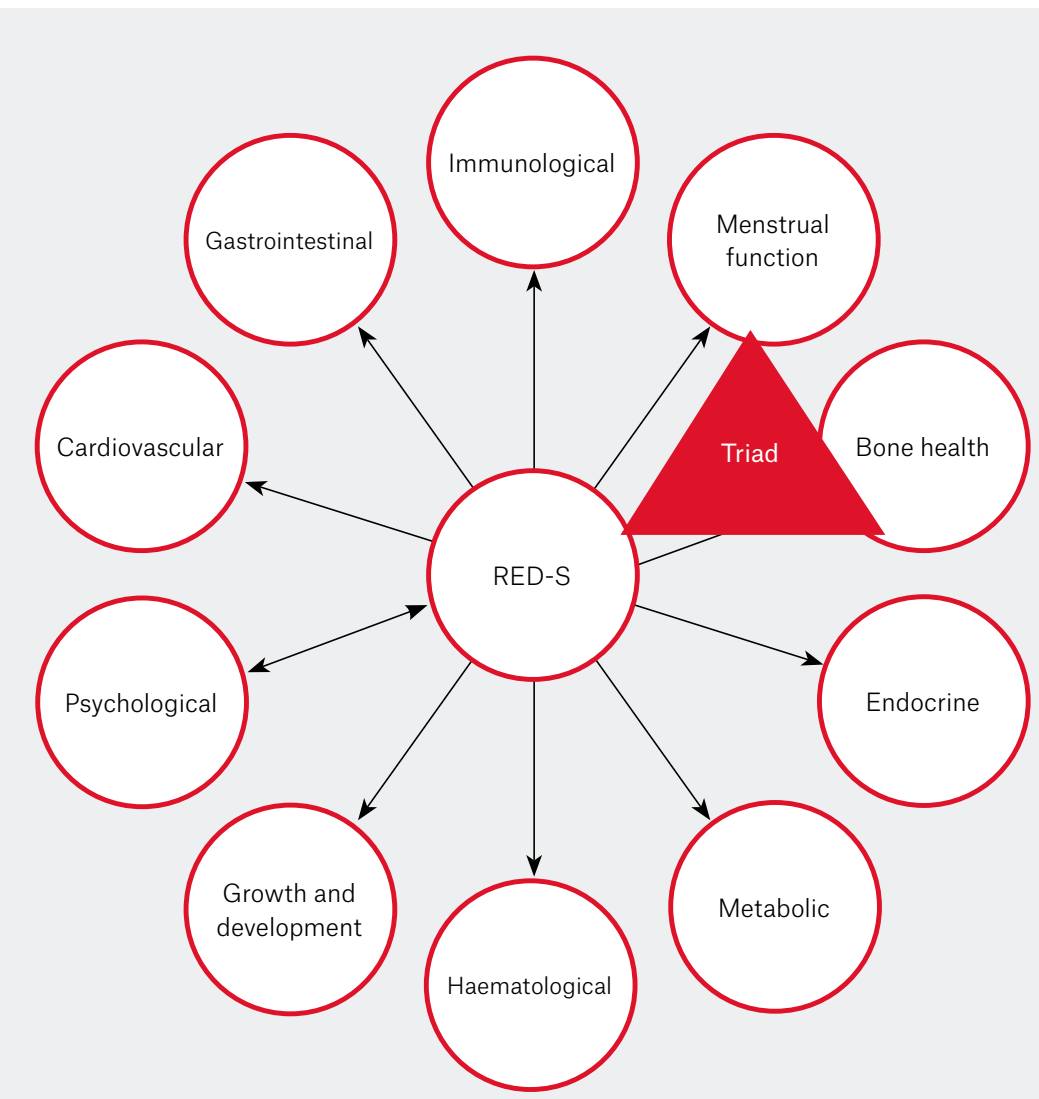

Figure 2. Health consequences of relative energy deficiency in sport (RED-S). 'Triad' refers to the female athlete triad. ${ }^{17}$

RED-S, relative energy deficiency in sport

Table 3. Overview of the Australian Institute of Sport (AIS) Sports Supplement Framework $^{14}$

\begin{tabular}{|c|c|c|}
\hline Category & Description & Examples \\
\hline A & $\begin{array}{l}\text { Supported for use in specific } \\
\text { situations in sport using } \\
\text { evidence-based protocols }\end{array}$ & $\begin{array}{l}\text { Sports foods/drinks } \\
\text { Medical supplements } \\
\text { Performance supplements }\end{array}$ \\
\hline B & $\begin{array}{l}\text { Deserving of further research and } \\
\text { could be considered for provision to } \\
\text { athletes under a research protocol or } \\
\text { case-managed monitoring situation }\end{array}$ & $\begin{array}{l}\text { Collagen support products } \\
\beta \text {-Hydroxy } \beta \text {-methylbutyrate (HMB) } \\
\text { Quercitin } \\
\text { Ketone supplements }\end{array}$ \\
\hline C & $\begin{array}{l}\text { Have little meaningful proof of } \\
\text { beneficial effects }\end{array}$ & $\begin{array}{l}\text { Any supplement not listed in A, B or D } \\
\text { categories }\end{array}$ \\
\hline D & $\begin{array}{l}\text { Banned or at high risk of } \\
\text { contamination with substances that } \\
\text { could lead to a positive drug test }\end{array}$ & $\begin{array}{l}\text { Stimulants } \\
\text { Prohormones and hormone boosters } \\
\text { Growth hormone releasers and } \\
\text { 'peptides' } \\
\text { Beta-2 agonists } \\
\text { Selective androgen receptor } \\
\text { modulators } \\
\text { Metabolic modulators }\end{array}$ \\
\hline
\end{tabular}




\section{Considerations and frequency of iron blood screening for athletes*}

\section{Variables to be considered}

- Minimum: serum ferritin, haemoglobin concentration, transferrin saturation

- Desirable: serum soluble transferrin receptor, haemoglobin mass, C-reactive protein

\section{Standardisation of blood collection}

- Time of day: preferably morning

- Hydration state: hydrated, preferably assessed by waking urinary specific gravity $(<1.025)$

- Low-to-moderate activity in the proceeding 24 hours

- No signs of sickness or infection

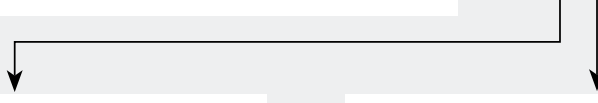

\section{Annually}

- No history of iron deficiency

- No history of irregular/excessive menses or amenorrhea

- No reports of fatigue after extended rest

- Strength/power-based sports with minimal endurance component

- No iron-related dietary restrictions

- No evidence of low energy availability

- No intention to undertake hypoxic training in the next 12 months

- No underlying pathology (eg coeliac or Crohn's disease)

\section{Biannually}

- Female

- Previous history ( $\geq 24$ months) of iron depletion (eg Stage $1^{\dagger}$ )

- Previous history ( $\geq 24$ months) of irregular/excessive menses

- Intention to undertake high training loads, especially in endurance and team-based sports

- Minimal (or zero) reports of prolonged fatigue after extended rest

- No iron-related dietary restrictions (eg non-vegetarian, non-vegan)

- No evidence of low energy availability

- Intention to undertake hypoxic training in the next 12 months

\section{Quarterly}

- Any recent history (<24 months) of iron depletion/deficiency (Stage 1, 2 or $3^{\dagger}$ ) irrespective of sex

- Any evidence of irregular/ excessive menses or amenorrhea

- High training loads in team and endurance-based sports

- Reporting prolonged fatigue/ lethargy even after extended rest

- Reduced work capacity during training

- Unexplained poor athletic performance

- Individuals restricting sources of dietary iron (eg vegetarian and vegan) or overall caloric intake

- Any evidence of low energy availability

- Intention to undertake hypoxic training in the next six months

Figure 3. Framework proposing considerations and the frequency of iron blood screening for athletes ${ }^{13}$

*Use of this framework requires the expertise of trained professionals including a physician, dietitian and sport physiologist. 'Stages of iron deficiency are defined by Peeling et al 2007.'2

Reproduced with permission from Sim M, Garvican-Lewis LA, Cox GR, et al, Iron considerations for the athlete: A narrative review, Eur J Appl Physiol 2019;119(7):1463-78, doi: 10.1007/s00421-019-04157-y.

and in addition provides many free evidence-based sports nutrition resources (www.sportsdietitians.com.au).

\section{Authors}

Ben Desbrow PhD, APD, Advanced Sports Dietitian, School of Allied Health Sciences, Griffith University, Qld.b.desbrow@griffithuni.edu.au

Gary Slater PhD, APD, Advanced Sports Dietitian,

School of Health and Sport Sciences, University of the Sunshine Coast, Qld; National Performance Nutrition Network Lead, Australian Institute of Sport, NSW
Gregory R Cox PhD, APD, Fellow Sports Dietitian Australia, Faculty of Health Sciences and Medicine, Bond University, Qld; Consultant to Paddle Australia and Triathlon Australia, NSW

Competing interests: None.

Funding: None.

Provenance and peer review: Commissioned, externally peer reviewed.

\section{References}

1. National Health and Medical Research Council. The Australian guide to healthy eating. Canberra: NHMRC, 2017. Available at www.eatforhealth.gov. au/guidelines/australian-guide-healthy-eating [Accessed 25 November 2019].
2. Dietitians Association of Australia. A modelling system to inform the revision of the Australian Guide to Healthy Eating. Canberra: National Health and Medical Research Council, 2011.

3. Thomas DT, Erdman KA, Burke LM. Position of the Academy of Nutrition and Dietetics, Dietitians of Canada, and the American College of Sports Medicine: Nutrition and athletic performance. J Acad Nutr Diet 2016;116(3):501-28. doi: 10.1016/j. jand.2015.12.006.

4. Burke LM, Castell LM, Casa DJ, et al. International Association of Athletics Federations consensus statement 2019: Nutrition for athletics. Int J Sport Nutr Exerc Metab 2019;29(2):73-84. doi: 10.1123/ ijsnem.2019-0065. 
5. Reguant-Closa A, Harris MM, Lohman TG, Meyer NL. Validation of the athlete's plate nutrition educational tool: Phase I. Int J Sport Nutr Exerc Metab 2019:1-26. doi: 10.1123/ijsnem.2018-0346.

6. Impey SG, Hearris MA, Hammond KM, et al. Fuel for the work required: $A$ theoretical framework for carbohydrate periodization and the glycogen threshold hypothesis. Sports Med 2018;48(5):1031-48. doi: 10.1007/s40279-0180867-7.

7. Black K, Slater J, Brown RC, Cooke R. Low energy availability, plasma lipids, and hormonal profiles of recreational athletes. J Strength Cond Res 2018;32(10):2816-24. doi: 10.1519/ JSC.0000000000002540.

8. Mountjoy M, Sundgot-Borgen J, Burke L, et al. The IOC consensus statement: Beyond the female athlete triad - relative energy deficiency in sport (RED-S). Br J Sports Med 2014;48(7):491-97. doi: 10.1136/bjsports-2014-093502.

9. Torstveit MK, Fahrenholtz I, Stenqvist TB, Sylta $\varnothing$, Melin A. Within-day energy deficiency and metabolic perturbation in male endurance athletes. Int J Sport Nutr Exerc Metab 2018;28(4):419-27. doi: 10.1123/ijsnem.2017-0337.

10. Papageorgiou M, Elliott-Sale KJ, Parsons A, et al. Effects of reduced energy availability on bone metabolism in women and men. Bone 2017;105:191-99. doi: 10.1016/j.bone.2017.08.019.

11. Ihle R, Loucks AB. Dose-response relationships between energy availability and bone turnover in young exercising women. J Bone Miner Res 2004;19(8):1231-40. doi: 10.1359/JBMR.040410.
12. Peeling $P$, Blee T, Goodman $C$, et al. Effect of iron injections on aerobic-exercise performance of iron-depleted female athletes. Int J Sport Nutr Exerc Metab 2007:17(3):221-31. doi: 10.1123/ ijsnem.17.3.221.

13. Sim M, Garvican-Lewis LA, Cox GR, et al. Iron considerations for the athlete: A narrative review. Eur J Appl Physiol 2019;119(7):1463-78. doi: 10.1007/s00421-019-04157-y.

14. Australian Institute of Sport. The AIS Sports Supplement Framework. ACT: AIS, 2019. Available at https://ais.gov.au/_data/assets/ pdf_file/0004/698557/AIS-Sports-SupplementFramework-2019.pdf [Accessed 2 December 2019].

15. Stewart AD, Sutton $L$, Stewart AD. A professional discipline and inter-disciplinary toolkit. In: Stewart $A D$, Sutton L, eds. Body composition in sport, exercise and health. Abingdon, UK: Routledge, 2012:187-208.

16. Jackson AS, Pollock ML. Practical assessment of body compositon. Phys Sports Med 1985;13:76-90.

17. Williams NI, Koltun KJ, Strock NCA, De Souza MJ. Female athlete triad and relative energy deficiency in sport: A focus on scientific rigor. Exerc Sport Sci Rev 2019:47(4):197-205. doi: 10.1249/ JES.0000000000000200. 